\title{
Novel Conjugated Polymer Containing Aromatic Ring and Selenium in Backbone. Side Reactions in the Addition Polymerization of Benzenediselenol to Diethynylbenzene
}

\author{
Eiichi Kobayashi, ${ }^{*}$ Nobuki Metaka, Sadahito Aoshima, \\ and Junji Furukawa \\ Department of Industrial Chemistry, Faculty of Science and Technology, \\ Science University of Tokyo, Noda, Chiba 278, Japan
}

(Received July 29, 1994)

\begin{abstract}
Irregular linkage in polymers obtained by the radical addition polymerization (so called polyaddition) of 1,4-benzenediselenol (BDSe) to 1,4-diethynylbenzene (DEB) was investigated. BDSe and DEB were polymerized by UV-irradiation in toluene at $60^{\circ} \mathrm{C}$ under nitrogen atmosphere to give a pale-yellowish polymer in $71 \%$ for $6 \mathrm{~min}$. A diselenide linkage was found in the obtained polymer by Raman spectroscopy. A coupling reaction between seleno radicals may occur in the course of the polymerization. The extent of diselenide linkage (-Se-Se-) was estimated to be one unit against $82 \pm 5$ repeating units $(-\mathrm{CH}=\mathrm{CH}-\mathrm{O}-\mathrm{CH}=\mathrm{CH}-\mathrm{Se}-\mathrm{O}-\mathrm{Se}-)$ from the Raman intensities of the diselenide linkage at $271 \mathrm{~cm}^{-1}$ relative to 1,4-diselenophenylene group (-Se-(0) $\mathrm{Se}-$ ) at $1055 \mathrm{~cm}^{-1}$. The effects of the polymerization conditions were also investigated. The coupling reaction between seleno radicals occurred more frequently when excess BDSe was used in the monomer feed ratio. The polymerization temperature and concentration of added oxygen in the reaction vessel affected little the diselenide linkage. The electrical conductivity of the polymers was of the order of $10^{-10} \mathrm{~S} \mathrm{~cm}^{-1}$ without dopant and $10^{-7} \mathrm{~S} \mathrm{~cm}^{-1}$ on $\mathrm{I}_{2}$ doping regardless of the content of the diselenide linkage in the polymers. The diselenide linkage in the polymers did not reflect appreciably the electrical conductivity of the polymer.
\end{abstract}

KEY WORDS Addition Polymerization / 1,4-Benzenediselenol / 1,4-

Diethynylbenzene / Polymer Containing Selenium / Coupling Reaction /

Diselenide Linkage / Irregular Structure / Raman Spectrum / Morero

Equation / Electrical Conductivity /

Selenol compounds dimerize through coupling reactions of seleno radicals generated with elimination of hydrogen atoms by oxygen molecules to give diselenide compounds. For example, the dimerization of benzeneselenols proceeds readily under atmospheric oxygen to give diphenyldiselenide quantitatively. ${ }^{1}$

Recently, the authors reported the synthesis of novel polymers containing selenium in the main chain by radical addition polymerization (so called polyaddition) of a diselenol monomer to an unsaturated compound such as a divinyl monomer or a diethynyl monomer. In the former case, addition polymerization of 1,4-benzenediselenol (BDSe) to 1,4-divinylbenzene (DVB) proceeded by radical initiator in toluene to give saturated polymer. ${ }^{2}$ The addition polymerization of BDSe to 1,4diethynylbenzene (DEB) proceeded in solution $^{3}$ or solid state ${ }^{4}$ by UV-irradiation to give the conjugated polymer $\mathbf{1}$.

$$
\begin{gathered}
\mathrm{HC} \equiv \mathrm{C}-\langle\mathrm{O}\rangle-\mathrm{C} \equiv \mathrm{CH}+\mathrm{HSe}-\langle\mathrm{O}\rangle-\mathrm{SeH} \rightarrow \\
(\mathrm{CH}=\mathrm{CH}-\langle\mathrm{O}\rangle-\mathrm{CH}=\mathrm{CH}-\mathrm{Se}-\langle\mathrm{O}\rangle-\mathrm{Se})_{n} \\
\mathbf{1}
\end{gathered}
$$

\footnotetext{
* To whom all correspondence should be addressed.
} 
However, selenium content in the obtained polymer was somewhat higher than that calculated assuming structure 1 . Side reactions increasing the selenium content in the polymer may occurred parallel with the polymerization. However, the side reactions in the addition polymerization have been scarcely investigated so far except for cases of the model addition reaction. ${ }^{5}$

In this article, the authors made quantitative analysis of irregular units in the polymer by Raman spectroscopy. For assignment of characteristic absorption bands in Raman spectrum, three model compounds were used. The effects of the polymerization conditions on the irregular structure were investigated. The relation between the structure and properties of the polymers is also discussed.

\section{EXPERIMENTAL}

\section{Monomers}

1,4-Benzenediselenol (BDSe) ${ }^{3}$ and 1,4-diethynylbenzene (DEB) ${ }^{6}$ were prepared by the previous method, $\mathrm{mp} 122.0-122.2^{\circ} \mathrm{C}$ (lit. ${ }^{3}$ $122.0-122.2^{\circ} \mathrm{C}$ ) and $96.5^{\circ} \mathrm{C}$ (lit. ${ }^{6} 96.5^{\circ} \mathrm{C}$ ), respectively. Benzeneselenol (BSe) was prepared according to the literature. ${ }^{1}$ Ethynylbenzene (EB; Tokyo Kasei Kogyo Co.) was obtained commercially. The monomers were purified by sublimation or vacuum distillation under nitrogen atmosphere.

\section{Polymerization}

Polymerization was carried out in a pyrex tube by mixing BDSe and DEB solutions in degassed dry toluene (Nacalai Tesque Inc.) at $60^{\circ} \mathrm{C}$ by UV-irradiation using $450 \mathrm{~W}$ high pressure mercury lamp (Ushio Co.) under nitrogen atmosphere. Toluene was purified by distillation over calcium hydride and degassed to exclude oxygen under reduced pressure for $20 \mathrm{~min}$ before use. Insoluble polymers in the polymerization solution were recovered by decantation under nitrogen atmosphere, washed with toluene, and dried under reduced pressure at room temperature overnight. For soluble polymers, the supernatant solution was poured into degassed methanol by a medical syringe under nitrogen atmosphere, and the precipitated polymer was recovered by centrifugation. After washing out residual monomers with methanol, the polymers were dried under reduced pressure at room temperature overnight. The effect of added oxygen on polymerization was evaluated as follows: each toluene solution of BDSe and DEB was introduced into a polymerization tube by a semi-closed method using a stainless pipe syphon under nitrogen atmosphere. Nitrogen gas $(99.99 \%)$ was purified by the previous method. ${ }^{7}$ The influence of oxygen on polymerization was investigated by the addition of a dry nitrogen-oxygen mixture in the polymerization tube.

\section{Model Compounds 2, 3, and 4}

Di-[4-( $\beta$-cis-styrylseleno)phenyl]diselenide 2 was prepared by a dimerization reaction of 4-( $\beta$-cis-styrylseleno)benzeneselenol under air. $1,4-\mathrm{Di}$-( $\beta$-cis-styrylseleno)benzene 3 was prepared by the addition reaction of BDSe to two molar equivalents of EBs. 1,4-Di- $(\beta$-cis-selenophenylethenyl)benzene 4 was similarly prepared by the addition reaction of two molar equivalents of BSes to DEB.

\section{4-( $\beta$-cis-Styrylseleno)benzeneselenol}

BDSe $(1.15 \mathrm{~g}, 4.9 \mathrm{mmol})$ and EB $(0.50 \mathrm{~g}$, $4.9 \mathrm{mmol}$ ) in $30 \mathrm{ml}$ of benzene (Nacalai Tesque Inc.) were charged in a $100 \mathrm{ml}$ flask, followed by stirring by a magnetic stirrer at room temperature for $8 \mathrm{~h}$ under nitrogen atmosphere. The reaction proceeded to give a reaction mixture containing 4 -( $\beta$-cis-styrylseleno)benzeneselenol, 1,4-di-( $\beta$-cis-styrylseleno)benzene 3 , and BDSe in a $2: 1: 1$ molar ratio by ${ }^{1} \mathrm{H}$ NMR. The reaction mixture was extracted five times with degassed $10 \mathrm{ml}$ of $5 \%$ aq. $\mathrm{NaOH}$ under nitrogen atmosphere, and the aqueous layer was poured into degassed $150 \mathrm{ml}$ of $6 \mathrm{~N}$ aq. $\mathrm{HCl}$ by a medical syringe yielding a white 
precipitate. This precipitate was filtered off, washed five times with each portion of $30 \mathrm{ml}$ of degassed water under nitrogen atmosphere, and dried under reduced pressure overnight. After removing residual BDSe by sublimation at $60^{\circ} \mathrm{C}(1 \mathrm{mmHg})$ for $4 \mathrm{~h}$, the residue was recovered as crude 4 - $(\beta$-cis-styrylseleno)benzeneselenol. Yield $0.79 \mathrm{~g}(48 \%)$. ${ }^{1} \mathrm{H}$ NMR: $\left[\mathrm{CS}_{2}\right.$, tetramethylsilane (TMS) standard], $\delta$ in ppm: $1.52(\mathrm{~s},-\mathrm{SeH}, 1 \mathrm{H}), 6.46$ and $6.75(\mathrm{ABq}$. vinylene, $\left.J_{\mathrm{CH}=\mathrm{CH}}=9.0 \mathrm{~Hz}, 2 \mathrm{H}\right), 7.0-7.4(\mathrm{~m}$, phenyl and phenylene, $9 \mathrm{H})$. However, isolation of 4 - $(\beta$-cis-styrylseleno)benzeneselenol in a pure form was difficult and the compound was used in the following reaction without further purification.

\section{Di-[4-( $\beta$-cis-styrylseleno) phenyl]diselenide $\mathbf{2}$}

4-( $\beta$-cis-Styrylseleno)benzeneselenol $(0.50 \mathrm{~g}$, $1.5 \mathrm{mmol}$ ) in a $100 \mathrm{ml}$ of methanol (Nacalai Tesque Inc.) was stirred at room temperature for $3 \mathrm{~h}$ under air. The reaction mixture was filtered off, and the solid residue was recovered as $\mathrm{di}-[4-(\beta$-cis-styrylseleno)phenyl $]$ diselenide 2. This compound was purified three times by a fractionation using GPC. Yield $0.03 \mathrm{~g}(6 \%)$. mp 103.7-104.4 ${ }^{\circ} \mathrm{C}$. ${ }^{1} \mathrm{H}$ NMR: $\left(\mathrm{CS}_{2}\right.$, TMS standard), $\delta$ in ppm: 6.50 and 6.79 (ABq. vinylene, $\left.J_{\mathrm{CH}=\mathrm{CH}}=9.7 \mathrm{~Hz}, 4 \mathrm{H}\right), 7.0-7.5(\mathrm{~m}$, phenyl and phenylene, $18 \mathrm{H})$. Se wt $\%: 46.3$ (Calcd 46.8).

\section{1,4-Di-( $\beta$-cis-styrylseleno $)$ benzene 3}

EB $(0.55 \mathrm{~g}, 5.4 \mathrm{mmol})$ was added to a solution of BDSe $(0.63 \mathrm{~g}, 2.7 \mathrm{mmol})$ in $20 \mathrm{ml}$ of benzene in a $50 \mathrm{ml}$ flask with stirring at room temperature for $8 \mathrm{~h}$ under nitrogen atmosphere. The reaction mixture was washed to exclude residual BDSe with $20 \mathrm{ml}$ of $5 \%$ aq. $\mathrm{NaOH}$ and $20 \mathrm{ml}$ of water. The organic layer was dried with anhydrous magnesium sulfate and the benzene solvent was evaporated. The residue was recrystallized twice in hexane-toluene $4: 1$ to give $1,4-\mathrm{di}$-( $\beta$-cis-styrylseleno)benzene 3 as a white-plate crystal. Yield $0.62 \mathrm{~g}(52 \%) \mathrm{mp}$ $138.9-139.6^{\circ} \mathrm{C}$. ${ }^{1} \mathrm{H}$ NMR: $\left(\mathrm{CS}_{2}\right.$, TMS stan- dard), $\delta$ in ppm: 6.55 and 6.84 (ABq. vinylene, $\left.J_{\mathrm{CH}=\mathrm{CH}}=8.7 \mathrm{~Hz}, 4 \mathrm{H}\right), 7.0-7.4(\mathrm{~m}$, phenyl and phenylene, 14H). Se wt\%: 35.6 (Calcd 35.7).

\section{1,4-Di-( $\beta$-cis-selenophenylethenyl)benzene 4}

BSe $(1.02 \mathrm{~g}, 6.4 \mathrm{mmol})$ was added to a solution of DEB $(0.41 \mathrm{~g}, 3.2 \mathrm{mmol})$ in $10 \mathrm{ml}$ of benzene in a $50 \mathrm{ml}$ flask with stirring and allowed to react at room temperature for $18 \mathrm{~h}$ under nitrogen atmosphere. The reaction mixture was washed to exclude residual BSe with $10 \mathrm{ml}$ of $5 \%$ aq. $\mathrm{NaOH}$ and $10 \mathrm{ml}$ of water. The organic layer was dried with anhydrous magnesium sulfate and the benzene solvent was evaporated. Recrystallization of the residue was conducted twice in hexane-toluene $4: 1$ to give 1,4-di-( $\beta$-cis-selenophenylethenyl)benzene 4 as a white-plate crystal. Yield $0.60 \mathrm{~g}(42 \%)$. mp 166.0-166.2 ${ }^{\circ} \mathrm{C} .{ }^{1} \mathrm{H}$ NMR: $\left(\mathrm{CS}_{2}\right.$, TMS standard), $\delta$ in ppm: 6.58 and 6.79 (ABq. vinylene, $\left.J_{\mathrm{CH}=\mathrm{CH}}=8.5 \mathrm{~Hz}, 4 \mathrm{H}\right), 7.0-7.5(\mathrm{~m}$, phenyl and phenylene, 14H). Se wt\%: 35.7 (Calcd 35.7).

\section{Measurements}

For characterization of monomers, polymers, and model compounds the following instruments were used: ${ }^{1} \mathrm{H}$ NMR: JEOL PMX-60si; IR: Hitachi 260-50; Raman: JEOL JRT-400T. The excitation line was $514.5 \mathrm{~nm}$ $(60 \mathrm{~mW})$ by a Toshiba LAI-104-A Ar-ion laser. An interference filter for $514.5 \mathrm{~nm}$ was placed in front of the sample to exclude emission lines. Raman spectra were recorded at a scan speed of $100 \mathrm{~cm}^{-1}$ per min and a $1.6 \mathrm{~s}$ time constant. Samples for Raman spectra of polymer and model compounds were measured in neat polymer pellets (thickness: ca. $0.1 \mathrm{~mm}$, press: $\left.20 \mathrm{~kg} \mathrm{~cm}^{-2}, 20 \mathrm{~s}\right)$ and in $\mathrm{CS}_{2}$ solution (24-38 mmoll $1^{-1}$ ) sealed in a glass capillary tube (diameter $2 \mathrm{~mm}$ ) at $22^{\circ} \mathrm{C}$, respectively. Raman spectral intensities at particular frequency were evaluated by peak area; GPC: JASCO TRI ROTAR instrument equipped with a polystyrene gel column (Shodex K-2002; inner diameter $20 \mathrm{~mm}$, length $300 \mathrm{~mm}$ ) and a 
refractive index detector. Chloroform was used as an eluent.

Electrical conductivity was measured by a two-terminal method with an Electro Multi Meter (Takeda Riken Co.) under nitrogen atmosphere at $23^{\circ} \mathrm{C}$. $\mathrm{I}_{2}$ doping was carried out by exposing the polymer powder to iodine vapor. The amount of the doped iodine was determined from gravimetric increase of the samples. Selenium content in polymers and model compounds was determined by Schoeniger's method. ${ }^{8}$ Molecular weight of the polymer $\bar{M}_{n}$ was measured by end group analysis, the so-called copper acetylide method. ${ }^{6}$

\section{RESULTS AND DISCUSSION}

Previously, the radical addition polymerization of 1,4-benzenediselenol (BDSe) to 1,4diethynylbenzene (DEB) was carried out to give novel conjugated polymers containing selenium in high yields. ${ }^{3}$ The obtained polymer was confirmed to have an alternating structure of BDSe and DEB by anti-Markownikoff's addition as shown in eq 1 by IR spectroscopy, $\bar{M}_{n}$, and quantitative analysis of selenium. Although study on electronic and thermal properties has been performed extensively, side reactions inducing an irregular diselenide linkage in the polymer have hardly been investigated.

By inspection of selenium content in the obtained polymer, its value was somewhat higher than the calculated value based on the structure 1. An irregular structure may increase selenium content in the polymer. The irregular structure was presumed to be the diselenide linkage (-Se-Se-) due to a coupling reaction of seleno radicals. Raman spectroscopy is suitable for the detection of the diselenide linkage, if it exists, since the diselenide linkage is a highly symmetric linkage and active for Raman spectroscopy. IR absorption of the diselenide linkage is very week, and not actually observed in IR spectrum of the obtained polymer in the $\mathrm{CsBr}$ disk. Therefore, the irregular structure was investigated by Raman spectroscopy. Equations for estimating the diselenide linkage in the polymer were derived based on the literature ${ }^{9}$ using equations for determining secondary structures of proteins by Raman spectroscopy.

\section{Model Compounds}

Model compounds are useful for determining the diselenide linkage in the polymer. Model compounds 3, 4, and 2 were prepared by the addition reaction of BDSe to ethynylbenzene (EB) or benzeneselenol (BSe) to DEB and dimerization of 4-( $\beta$-cis-styrylseleno)benzeneselenol, respectively. In the ${ }^{1} \mathrm{H}$ NMR spectrum of model compound 2, four protons of the vinylene group are centered at 6.50 and $6.79 \mathrm{ppm}$ as an $\mathrm{AB}$ quartet type. The coupling constant $J_{\mathbf{C H}=\mathbf{C H}}$ of the vinylene protons is $9.7 \mathrm{~Hz}$ indicating the cis-linkage. Similarly, the coupling constants $J_{\mathrm{CH}=\mathrm{CH}}$ for $A B$ quartet vinylene protons of the model compounds 3 and 4 are 8.7 and $8.5 \mathrm{~Hz}$, respectively, which indicate the cis-linkage.

$$
\begin{aligned}
& \text { (0) }-\mathrm{CH}=\mathrm{CH}-\mathrm{Se}-(\mathrm{O}-\mathrm{Se}-\mathrm{Se}-(\mathrm{O}-\mathrm{Se}-\mathrm{CH}=\mathrm{CH}-\mathrm{O} \quad 2 \\
& \text { (0) }-\mathrm{CH}=\mathrm{CH}-\mathrm{Se}-\langle\mathrm{O}\rangle-\mathrm{Se}-\mathrm{CH}=\mathrm{CH}-\text { (O) } 3 \\
& \text { (0) }-\mathrm{Se}-\mathrm{CH}=\mathrm{CH}-\langle\mathrm{O}\rangle-\mathrm{CH}=\mathrm{CH}-\mathrm{Se}-(\mathrm{O}\rangle
\end{aligned}
$$

These assignments are consistent with ${ }^{1} \mathrm{H}$ NMR data taken with the cis adduct $(10.2 \mathrm{~Hz})$ of BSe and EB. ${ }^{5}$ The microstructure of the polymer was also mainly the cis structure regardless of the polymerization conditions. For example, the polymer shown in Figure 2 has $86 \%$ cis structure. ${ }^{3}$ Therefore, model compounds 2,3 , and 4 having the $c i s$ structure may be regarded as models for the structure of the polymer.

Figure 1 shows the Raman spectra of the model compounds 2,3 , and 4 . The $-\mathrm{Se}-\mathrm{Se}-$ stretching vibration of the model compound 2 appears at $271 \mathrm{~cm}^{-1}$. The $-\mathrm{CH}=$ in-plane deformation vibrations of 1,4 -phenylene $(-\langle 0\rangle-)$ 


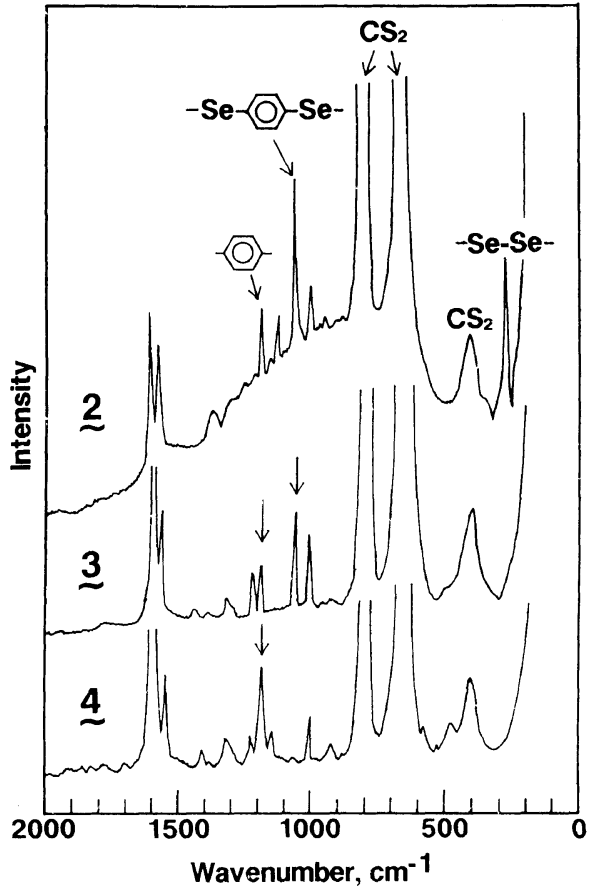

Figure 1. Raman spectra of the model compounds 2, 3, and 4 in $\mathrm{CS}_{2}$ at $23^{\circ} \mathrm{C}$.

2 (a) $-\mathrm{CH}=\mathrm{CH}-\mathrm{Se}-$ (O) $-\mathrm{Se}-\mathrm{Se}-(\mathrm{O}-\mathrm{Se}-\mathrm{CH}=\mathrm{CH}-$ (O)

3 (a) $\mathrm{CH}=\mathrm{CH}-\mathrm{Se}-(\mathrm{O}-\mathrm{Se}-\mathrm{CH}=\mathrm{CH}-(\mathrm{O}$

4 (O) $-\mathrm{Se}-\mathrm{CH}=\mathrm{CH}-$ (O) $\mathrm{CH}=\mathrm{CH}-\mathrm{Se}-(\mathrm{O}$

rings of the model compounds $\mathbf{2}, \mathbf{3}$, and $\mathbf{4}$ can be assigned at 1178,1184 , and $1186 \mathrm{~cm}^{-1}$, respectively. The $-\mathrm{CH}=$ in-plane deformation vibration of 1,4-phenylene ring adjacent to selenium atoms is very sensitive to the mass effect $^{10}$ of selenium groups. For compounds 2 and 3, characteristic vibrations of 1,4diselenophenylene ( $-\mathrm{Se}-$ (O)- $\mathrm{Se}-$ ) group can be found at 1054 and $1060 \mathrm{~cm}^{-1}$, respectively. The scattering coefficients of Raman lines corresponding to an extinction coefficients of IR absorption should be expressed as relative values, since Raman lines are secondary scattering light and do not give absolute intensities. In this paper, the scattering coefficient of $-\mathrm{Se}-\mathrm{Se}-$ stretching vibration at $271 \mathrm{~cm}^{-1}$ was used as a reference (100) and
Table I. Raman spectroscopic data in $\mathrm{CS}_{2}$ at $22^{\circ} \mathrm{C}$

\begin{tabular}{|c|c|c|c|}
\hline \multirow{2}{*}{$\begin{array}{c}\text { Model } \\
\text { compound }\end{array}$} & \multirow{2}{*}{ Assignment } & \multirow{2}{*}{$\frac{\text { Wavenumber }}{\mathrm{cm}^{-1}}$} & \multirow{2}{*}{$\begin{array}{l}\text { Relative } \\
\text { scattering } \\
\text { coefficient }\end{array}$} \\
\hline & & & \\
\hline \multirow{3}{*}{2} & $-\mathrm{Se}-\mathrm{Se}-$ & 271 & 100 \\
\hline & ${ }_{-} \mathrm{Se}-(\mathrm{O})-\mathrm{Se}-$ & 1054 & 72.7 \\
\hline & & 1178 & 14.9 \\
\hline \multirow{2}{*}{3} & $-\mathrm{Se}-\langle\mathrm{O}-\mathrm{Se}-$ & 1060 & 20.2 \\
\hline & & 1184 & 12.6 \\
\hline 4 & - & 1186 & 37.1 \\
\hline
\end{tabular}

2 (O) $\mathrm{CH}=\mathrm{CH}-\mathrm{Se}-\mathrm{O}-\mathrm{Se}-\mathrm{Se}-\mathrm{O}-\mathrm{Se}-\mathrm{CH}=\mathrm{CH}-\mathrm{O}$ Concentration, $24 \mathrm{mmoll}^{-1}$

3 (O) $-\mathrm{CH}=\mathrm{CH}-\mathrm{Se}-\mathrm{O}-\mathrm{Se}-\mathrm{CH}=\mathrm{CH}-\mathrm{O}$ Concentration, $38 \mathrm{mmoll}^{-1}$

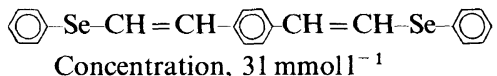

other scattering coefficients are expressed as relative values against the reference value.

Table I summarizes the Raman spectroscopic data of the model compounds in $\mathrm{CS}_{2}$ solution at $22^{\circ} \mathrm{C}$.

The scattering coefficients of $-\mathrm{Se}-\mathrm{Se}-$ stretching vibration and $-\mathrm{CH}=$ in-plane deformation vibrations of 1,4-diselenophenylene and 1,4-phenylene cannot be directly determined because of the insolubility of polymers in conventional organic solvents. Accordingly, the scattering coefficients used for determining the diselenide linkage in polymers were tentatively deduced from the values of the model compounds in $\mathrm{CS}_{2}$. The relation between the intensities of the diselenide linkage at $271 \mathrm{~cm}^{-1}\left(I_{271}\right), 1,4$-diselenophenylene group at $1055 \mathrm{~cm}^{-1}\left(I_{1055}\right)$, and $1,4-$ phenylene group at $1178 \mathrm{~cm}^{-1}\left(I_{1178}\right)$ was determined by the following Morero equation, where $X_{1}, X_{2}$, and $X_{3}$ mean the mole fractions of $=\mathrm{CH}-\mathrm{Se}-(\mathrm{O}\rangle-\mathrm{Se}-\mathrm{Se}-(\mathrm{O})-\mathrm{Se}-\mathrm{CH}=$, 
$=\mathrm{CH}-\mathrm{Se}-(\mathrm{O}-\mathrm{Se}-\mathrm{CH}=$, and $=\mathrm{CH}-(\mathrm{O})-\mathrm{CH}=$ in polymers, respectively.

$$
\begin{gathered}
C I_{271}=100 X_{1} \\
C I_{1055}=72.7 X_{1}+20.2 X_{2} \\
C I_{1178}=14.9 X_{1}+12.6 X_{2}+37.1 X_{3} \\
X_{1}+X_{2}+X_{3}=1 \\
C, \text { constant }
\end{gathered}
$$

Although these equations can be used for estimation of the diselenide linkage in polymers, the diselenide linkage in polymers evaluated by this method may have some error, since the scattering coefficients of polymers are not only assumed to be the same as those of the model compounds, but the Raman spectra of the polymers were also measured by the neat polymer pellet method.

\section{Raman Spectrum of Polymer 1 and Diselenide Linkage}

Figure 2 shows the Raman spectrum of the obtained polymer. The assignment of the spectrum in Figure 2 was done using

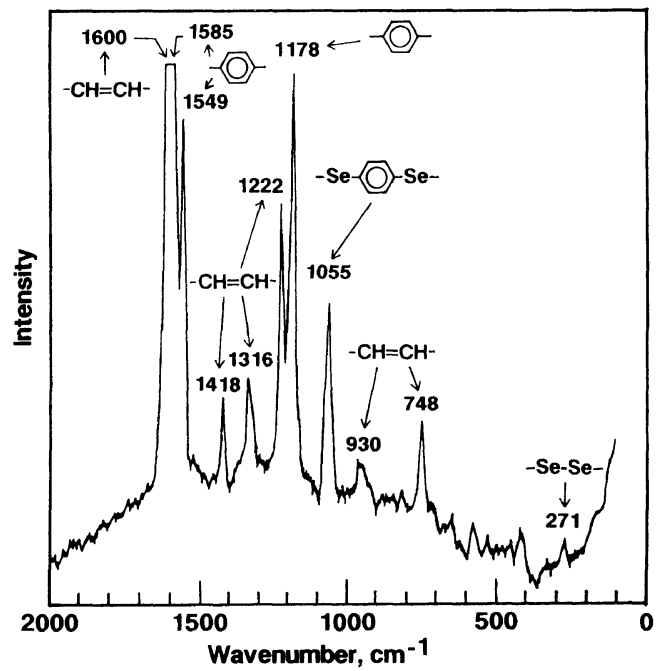

Figure 2. Raman spectrum of polymer 1. Polymerization conditions: $[\mathrm{BDSe}]_{0}=[\mathrm{DEB}]_{0}=0.05 \mathrm{moll}^{-1}$ in toluene at $60^{\circ} \mathrm{C}$ for $6 \mathrm{~min}$ by $450 \mathrm{~W}$ high pressure mercury lamp under nitrogen atmosphere. Yield $=71 \%$ (insoluble part $64 \%$ ); $\bar{M}_{\mathrm{n}}=29000 ;$ Se wt $\%=44.9($ Calcd 43.6$)$. the following compounds: BDSe, 1,4-divinylbenzene (DVB), model compounds 2, 3, 4, $\left.{ }^{-} \mathrm{CH}_{2} \mathrm{CH}_{2}-\mathrm{OO}-\mathrm{CH}_{2} \mathrm{CH}_{2}-\mathrm{Se}-\mathrm{O}-\mathrm{Se}\right)_{n}$, $\left(\mathrm{CH}=\mathrm{CH}-(\mathrm{O})-\mathrm{CH}=\mathrm{CH}-\mathrm{S}-(\mathrm{O}-\mathrm{S})_{n}, \quad\right.$ and poly ( $p$-phenylenevinylene). ${ }^{11}$ The peak at 271 $\mathrm{cm}^{-1}$ was confirmed to be the diselenide linkage by the model compound $\mathbf{2}$. The side reaction was the coupling reaction of seleno radicals generated from the selenol group with an elimination of hydrogen atom. The $\mathrm{C}=\mathrm{C}$ skeletal stretching mode and $-\mathrm{CH}=$ in-plane deformation vibrations of the phenylene group could be found at $1500-1600$ and $1000-1200$ $\mathrm{cm}^{-1}$, respectively. Interestingly, the vibration at $1055 \mathrm{~cm}^{-1}$ characteristically originates from only 1,4-diselenophenylene group ( $-\mathrm{Se}-(\mathrm{O})-\mathrm{Se}-$ ). The $\mathrm{C}=\mathrm{C}$ stretching mode, $-\mathrm{CH}=$ in-plane and $-\mathrm{CH}=$ out-of-plane deformation vibrations of vinylene groups were found at 1600 , $1200-1450$, and $700-950 \mathrm{~cm}^{-1}$, respectively.

The characteristic vibrations of the diselenide linkage, 1,4-diselenophenylene group, and 1,4-phenylene group appear at 271, 1055 , and $1178 \mathrm{~cm}^{-1}$, respectively, in the Raman spectrum of the polymer (Figure 2). Using eqs 2-5, the diselenide linkage in the polymer shown in Figure 2 was estimated as one unit per $82 \pm 5$ repeating units ( $-\mathrm{CH}=\mathrm{CH}-(\mathrm{O})-\mathrm{CH}=\mathrm{CH}-\mathrm{Se}-(\mathrm{O})-\mathrm{Se}-$ ). This indicates that one coupling reaction of seleno radicals occurs while $164 \pm 10$ addition reactions of selenol groups to ethynyl groups take place.

The effects of polymerization conditions such as monomer feed ratio, polymerization temperature, and effects of added oxygen were investigated to make clear factors for the formation of the diselenide linkage. Tables II, III, and IV show polymerization data. Figure 3 shows the relation between monomer feed ratio and diselenide linkage or selenium content in polymers. Figures 4 and 5 show the effects of polymerization temperature and concentration of added oxygen. 
Side Reaction in Addition Polymerization of BDSe to DEB

Table II. Effects of monomer feed ratio ${ }^{a}$

\begin{tabular}{|c|c|c|c|}
\hline$[\mathrm{BDSe}]_{0}$ & \multicolumn{2}{|c|}{ Yield $/ \%^{b}$} & $\bar{M}_{n} \times 10^{-4 \mathrm{c}}$ \\
\hline$[\mathrm{BDSe}]_{0}+[\mathrm{DEB}]_{0}$ & Insol. & Sol. & Insol. \\
\hline 0.40 & 57 & 5 & $2.1^{\mathrm{d}}$ \\
\hline 0.45 & 51 & 8 & 2.0 \\
\hline 0.50 & 56 & 5 & $3.7^{\mathrm{d}}$ \\
\hline 0.55 & 60 & 6 & $2.0^{\mathrm{d}}$ \\
\hline 0.60 & 77 & 9 & $0.9^{d}$ \\
\hline
\end{tabular}

${ }^{\text {a }}[\mathrm{BDSe}]_{0}+[\mathrm{DEB}]_{0}=0.1 \mathrm{moll}^{-1}$ in toluene at $60^{\circ} \mathrm{C}$ for $4 \mathrm{~min}$ by $\mathrm{UV}$-irradiation $(450 \mathrm{~W}$ high pressure mercury lamp) under nitrogen atmosphere.

b Yield calculated based on the minor monomer in the feed.

c Copper acetylide method.

d Used for electrical conductivity shown in Figure 6.

Table III. Effects of polymerization temperature ${ }^{\mathrm{a}}$

\begin{tabular}{ccccc}
\hline \multirow{2}{*}{ Temperature $/{ }^{\circ} \mathrm{C}$} & \multicolumn{2}{c}{ Yield $/ \%{ }^{\mathrm{b}}$} & & $\bar{M}_{n} \times 10^{-4 \mathrm{c}}$ \\
\cline { 2 - 3 } \cline { 5 - 5 } & Insol. & Sol. & & Insol. \\
\hline 60 & 56 & 5 & & 2.9 \\
25 & 54 & 6 & & 2.2 \\
0 & 54 & 5 & & 1.9 \\
-20 & 56 & 3 & & 1.6
\end{tabular}

a $[\mathrm{BDSe}]_{0}=[\mathrm{DEB}]_{0}=0.05 \mathrm{moll}^{-1}$ in toluene for $4 \mathrm{~min}$ by UV-irradiation ( $450 \mathrm{~W}$ high pressure mercury lamp) under nitrogen atmosphere.

b Yield measured by gravimetry.

c Copper acetylide method.

In the case of the effects of the monomer feed ratio, the diselenide linkage in polymers was found to increase with the feed ratio of BDSe. Selenium content in polymers increased with diselenide linkage. The reason for this is considered as follows: seleno radicals are liable to combine owing to increase in the relative concentration of the seleno radical. However, the diselenide linkage was present in polymers, even when selenium content is lower than that calculated assuming structure $\mathbf{1}$. Side reactions of DEB such as a cyclization ${ }^{12}$ and polymerization $^{12}$ might occur. In the model addition reaction of benzenethiol to ethynylbenzene, compound 5 containing the dimerized linkage of EB was confirmed to be $c a .0 .7 \mathrm{wt} \%{ }^{7}$
Table IV. Effects of conentration of added oxygen ${ }^{\mathrm{a}}$

\begin{tabular}{ccccc}
\hline & \multicolumn{2}{c}{$\left.\mathrm{O}_{2}\right]_{0} \times 10^{6}, \mathrm{moll}^{-1} \mathbf{b}$} & \multicolumn{2}{c}{$\bar{M}_{n} \times 10^{-\mathbf{4} \mathrm{e}}$} \\
\cline { 2 - 3 } \cline { 5 - 5 } & Insol. & Sol. & & Insol. \\
\hline 0 & 19 & 19 & & 0.63 \\
2 & 23 & 16 & & 0.78 \\
4 & 24 & 15 & & 1.3 \\
8 & 26 & 14 & & 1.3 \\
20 & 29 & 13 & & 1.4 \\
40 & 32 & 12 & & 1.7 \\
$200^{\mathrm{c}}$ & 46 & 10 & & 1.0
\end{tabular}

a $[\mathrm{BDSe}]_{0}=[\mathrm{DEB}]_{0}=0.05 \mathrm{moll}^{-1}$ in toluene at $60^{\circ} \mathrm{C}$ for $15 \mathrm{~min}$ by $\mathrm{UV}$-irradiation $(450 \mathrm{~W}$ high pressure mercury lamp) under nitrogen atmosphere.

b Oxygen concentration in nitrogen atmosphere.

c $200 \times 10^{-6} \mathrm{moll}^{-1}$ oxygen corresponds to $\mathrm{ca} .40 \mathrm{ppm}$ when all of oxygen dissolve in toluene.

d Yield measured by gravimetry.

e Copper acetylide method.

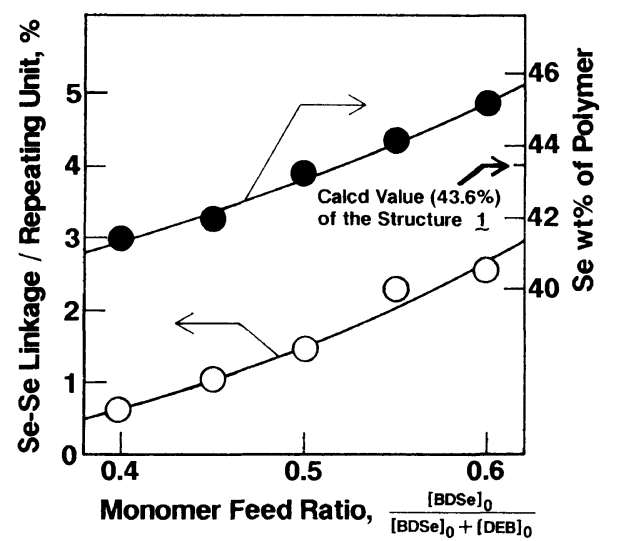

Figure 3. Relation between the monomer feed ratio and diselenide linkage or the selenium content in polymers (insoluble parts in Table II).

Accordingly, the homosequence of DEBs in<smiles>O=CC=C(O)C=O</smiles>

the polymer is expected to be conjugated double bonds with an aromatic ring. This structural unit generally has an absorption at $1625 \mathrm{~cm}^{-1}$ in IR spectroscopy. ${ }^{13}$ In the IR spectra of polymers, absorptions near 1625 $\mathrm{cm}^{-1}$ increase with the feed ratio of DEB. 


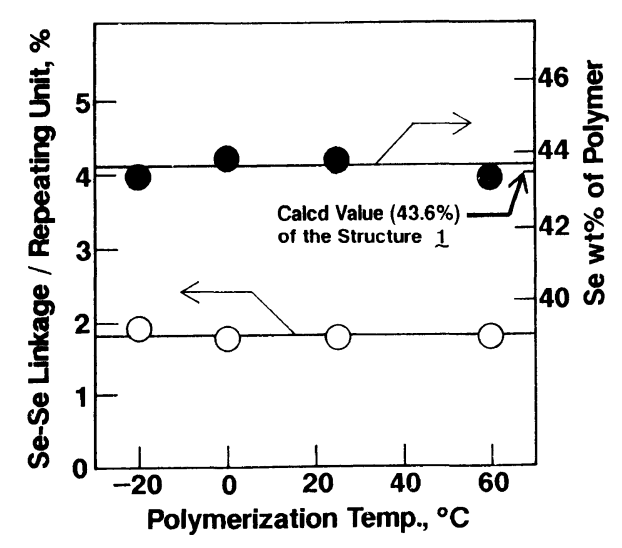

Figure 4. Relation between the polymerization temperature and diselenide linkage or the selenium content in polymers (insoluble parts in Table III).

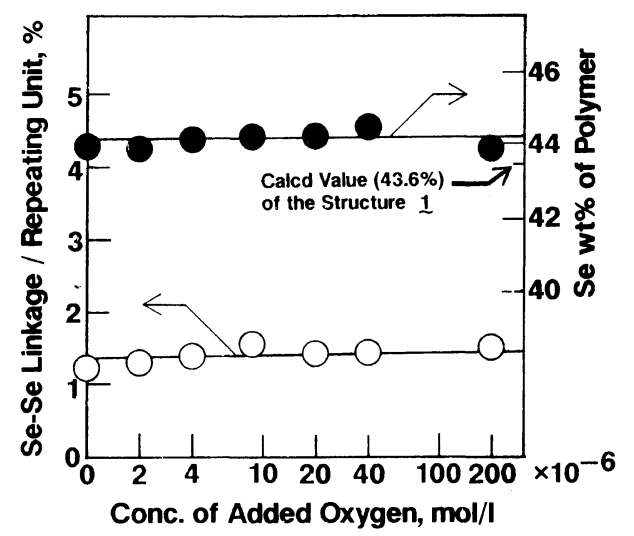

Figure 5. Relation between the concentration of added oxygen and diselenide linkage or the selenium content in polymers (insoluble parts in Table IV).

Therefore, oligo-DEB units can be incorporated into the main chain of the polymer. However, quantitative determination is difficult because the absorption is weak. Consequently, the addition polymerization of BDSe to DEB might have essentially somewhat irregular sequences of DEB-DEB and BDSeBDSe diads.

The extent of diselenide linkage and selenium content in polymers were found approximately constant regardless of polymerization temperature (Figure 4). The apparent activation energy of the coupling reaction of seleno radicals is almost $0 \mathrm{kcal} \mathrm{mol}^{-1}$, similar to conventional radical polymerizations.

As effects of the concentration of added oxygen, the polymer yield increases with the concentration of added oxygen, but the diselenide linkage and selenium content in polymers are independent of the concentration of added oxygen. Oxygen behaves merely as a radical initiator, like UV-irradiation.

\section{Polymer Structure and Property}

Polymer 1 has a conjugated $\pi$ system. Therefore, $\mathbf{1}$ is a semiconductor of the order of $10^{-5} \mathrm{~S} \mathrm{~cm}^{-1}$ on $\mathrm{I}_{2}$ doping $\left(1.0 \mathrm{I}_{2} \mathrm{~mol}\right.$ per repeating unit). ${ }^{3}$ The diselenide linkage (-Se-Se-) may disturb the conjugated $\pi$ system of the polymer, since the electrical conductivity of the polymer of 1,4-benzenedithiol and DEB was of the order of $10^{-3} \mathrm{~S} \mathrm{~cm}^{-1}$ on $\mathrm{I}_{2}$ doping. ${ }^{6}$ Disturbance of the conjugated $\pi$ system by the diselenide linkage is suggested by UV spectra of the model compounds $\mathbf{2}$ and 3. Absorption maxima of $\mathbf{2}$ and $\mathbf{3}$ were seen at 281 and $312 \mathrm{~nm}$, respectively. The absorption maximum of 3 without the diselenide linkage shifted to a longer wavelength than that of $\mathbf{2}$ with the diselenide linkage, indicating that electrons of 2 require higher excitation energy than those of 3. Therefore, the diselenide linkage disturbs the conjugated $\pi$ system of the polymer. The main chain scission of the polymer is unlikely by reaction 'of the diselenide linkage and $\mathrm{I}_{2}$, since the diselenide linkage and $\mathrm{I}_{2}$ form merely a charge transfer complex. ${ }^{14}$

Figure 6 shows the relation between the content of the diselenide linkage in polymers and electrical conductivity. The electrical conductivity of the polymers was of the order of $10^{-10} \mathrm{~S} \mathrm{~cm}^{-1}$ without doping. Doping rate increased with the content of the diselenide linkage. However, the electrical conductivity of the polymers was of the order of $10^{-7} \mathrm{~S} \mathrm{~cm}^{-1}$ at $0.82-0.84 \quad \mathrm{I}_{2}$ mol per repeating unit regardless of the content of the diselenide linkage in polymers. The irregular structures in the polymers such as the diselenide linkage 


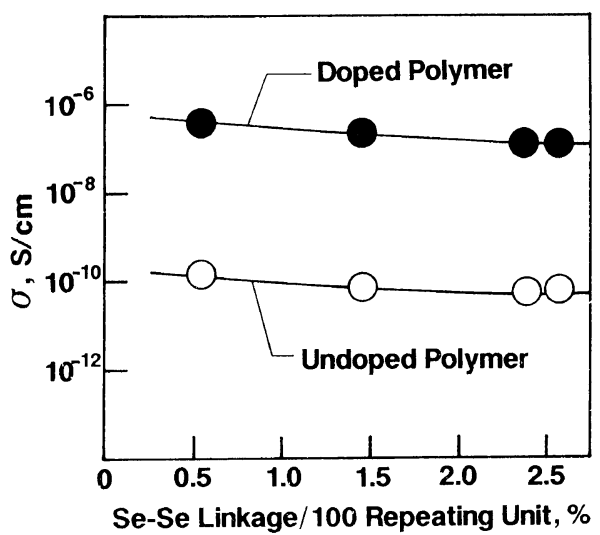

Figure 6. Relation between the content of diselenide linkage in polymers and electrical conductivity at $23^{\circ} \mathrm{C}$ under nitrogen atmosphere. Polymerization conditions: see Table II. Doped $\mathrm{I}_{2}: 0.82-0.84$ per repeating unit.

did not reflect the electrical conductivity of the polymers so much.

The electrical conductivity of polymers is related to intramolecular and intermolecular conjugations. In studies on polyacetylene, ${ }^{15,16}$ high electrical conductivity of doped polyacetylene was confirmed to depend on highly orientated macromolecules. Consequently, the electrical conductivity of the polymer 1 may be controlled more effectively by ordered macromolecular orientation than the primary structure of a polymer.

\section{CONCLUSIONS}

The diselenide linkage was detected by Raman spectroscopy in polymer 1. The side reaction was a coupling reaction of seleno radicals, which occurred more frequently when BDSe was rich in the monomer feed ratio. The electrical conductivity of the polymer was approximately constant regardless of the content of the diselenide linkage in the polymers.

\section{REFERENCES}

1. G. Foster, Org. Synth., Collect. Vol. III, 771 (1955).

2. E. Kobayashi, Y. Akiba, and S. Aoshima, J. Polym. Sci., A, Polym. Chem., 32, 1609 (1994).

3. E. Kobayashi, N. Metaka, S. Aoshima, and J. Furukawa, J. Polym. Sci., A, Polym. Chem., 30, 227 (1992).

4. E. Kobayashi, N. Metaka, S. Aoshima, and J. Furukawa, Polym. Prepr. Jpn., 39, 1648 (1990).

5. N. Metaka, E. Kobayashi, S. Aoshima, and J. Furukawa, Polym. J., 27, 156 (1995).

6. E. Kobayashi, T. Ohashi, and J. Furukawa, Makromol. Chem., 187, 2525 (1986).

7. E. Kobayashi, T. Obata, S. Aoshima, and J. Furukawa, Polym. J., 22, 1035 (1990).

8. K. Mori, Y. Kamimori, and Y. Nakamura, Nippon Kagakukaishi, 9, 1520 (1956).

9. J. L. Lippert, D. Tyminski, and P. J. Desmeules, J. Am. Chem. Soc., 98, 7075 (1976).

10. D. Herrmann, J. Prakt. Chem., 320, 231 (1978).

11. Y. Furukawa, A. Sakamoto, and M. Tasumi, J. Phys. Chem., 93, 5354 (1989).

12. S. Amdur, A. T. Y. Cheng, C. J. Wong, and P. Ehrlich, J. Polym. Sci., A, Polym. Chem., 16, 407 (1978).

13. L. J. Bellamy, "The Infra-red Spectra of Complex Molecules," Chapman and Hall, London, 1975, p 46.

14. L. A. Sorokina, T. I. Chebotar, and L. M. Kateaeva, Zh. Fiz. Khim., 50, 776 (1976).

15. J. Tsukamoto, A. Takahashi, and K. Kawasaki, J. Appl. Phys. Jpn., 29, 125 (1990).

16. J. Tsukamoto and A. Takahashi, Synth. Metals, 41, 7 (1987). 